\title{
Unusual Presentation of a Metastatic Esophageal Carcinoma
}

\author{
Katarzyna Orlicka Stéphanie Maynard Mickael Bouin \\ Department of Gastroenterology, Centre hospitalier de l'Université de \\ Montréal, Montréal, Canada
}

\section{Key Words}

Abdominal mass · Esophageal cancer $\cdot$ Squamous esophageal carcinoma

\begin{abstract}
Esophageal cancer most commonly presents with upper digestive symptoms such as dysphagia. Lymph nodes are among the most common metastatic sites of this type of cancer. We report the case of a 53-year-old man presenting with unusual sole presenting features of esophageal cancer. The patient sought medical attention for abdominal pain without dysphagia, which was first investigated with an abdominal computed tomography scan. A large abdominal mass was discovered on imaging. Biopsies of this mass were in keeping with esophageal squamous cell cancer. With this finding, gastroscopy was performed, confirming the presence of primary esophageal cancer. This is a rare presentation of esophageal cancer without upper gastrointestinal symptoms. This case reinforces the value of biopsy for any neoplastic mass, especially in a context of unusual symptoms.
\end{abstract}

\section{Introduction}

Esophageal cancer is the fifth leading cause of death in men from cancer worldwide [1]. In 2009 in Canada, there were 1,600 estimated new cases of esophageal cancer, representing less than $1 \%$ of the 2008 anticipated incidence of cancer. Men were more affected with 1,200 estimated new cases [2]. The median age at diagnosis is 68 years [3].

There are two majors types of esophageal cancer: esophageal squamous cell cancer (ESCC) and esophageal adenocarcinoma (EAC). Together, they represent more than $90 \%$ of primary esophageal carcinomas. There are numerous identifiable risk factors. Tobacco use and previous radiotherapy for breast cancer are major know risk factors for both EAC and ESCC [4]. ESCC risk is also increased with alcohol consumption, 
caustic injury to the esophagus, achalasia, tylosis (nonepidermolytic palmoplantar keratoderma), Plummer-Vinson syndrome and a history of head and neck cancer. The known risk factors for EAC are chronic gastroesophageal reflux disease and Barrett's esophagus [5].

Clinical presentation is similar for all types of esophageal cancers. The most common symptoms are dysphagia and odynophagia [1]. Other less common ones include hoarseness, cough and dyspnea [4]. More than a third of patients with ESCC present with metastatic disease. The metastases are usually in the lymph nodes, liver, lungs and bones [1].

The initial investigation includes an upper endoscopy or a barium-swallow exam. To exclude metastasis, a computed tomography (CT) scan of the chest, abdomen and pelvis should be performed [4]. The stages of esophageal cancer are defined according to the American Joint Committee on Cancer Staging system. Treatment is based on this staging and includes endoscopic mucosal resection, surgery, radiotherapy and chemotherapy [5].

\section{Case Report}

A 53-year-old Caucasian man sought medical attention for a 4-week history of upper abdominal pain. He had no medical history besides chronic drinking for 35 years and active smoking of 25 packs per year. He denied having any abdominal symptoms in the past. The pain was constant and located in the epigastrium, spreading to his back. It was associated with immediate postprandial fullness, nausea and vomiting. He denied having dysphagia or odynophagia. Over a period of 3 months, he developed anorexia with an aversion to food, drinking only liquids. He lost 40 pounds, which represented $21 \%$ of his total weight.

On physical examination, the patient was underweight with normal vital signs. Abdominal examination revealed present bowel sounds and an epigastric mass that was firm, fixed and non-pulsatile. He did not have abdominal tenderness, organomegaly or adenomegaly. His rectal examination was normal. The remainder of the examination was unremarkable.

Initial laboratory results showed a hemoglobin level of $136 \mathrm{~g} / \mathrm{l}$ (normal 135-170 g/l) with a hematocrit of 39.7\% (normal 42-50\%). Amylase level was $149 \mathrm{U} / \mathrm{l}$ (normal 0-100 U/l) and lipase $201 \mathrm{U} / \mathrm{l}$ (normal 0-60 U/l). The rest of the blood results were all normal. Tumor markers were within normal ranges, including carcinogenic embryonic antigen and carbohydrate antigen 19-9.

A CT scan revealed a heterogeneous lesion with necrotic tissue localized beneath the pancreatic gland, at the mesenteric root (fig. 1). The mass was pushing the pancreas forward and was invading vascular structures of the celiac trunk and the superior mesenteric artery. Some retroperitoneal suspicious lymph nodes were also noted. The rest of the CT was within normal limits, including the renal and urinary systems. It was impossible for the radiologists to determine the exact origin of this tumor on imaging.

Considering the retropancreatic localization of the mass, an upper endoscopic ultrasound (EUS) was performed to obtain tissue samples for histology. It demonstrated extrinsic compression of the stomach along the lesser curvature by this heterogeneous mass, which measured more than $6 \mathrm{~cm}$ (fig. 2). It was invading the celiac trunk and the superior mesenteric artery, as described on the CT. The mass seemed to arise neither from the stomach nor the pancreas. Biopsies were performed by EUS-guided transgastric fine-needle aspiration (19-gauge Echotip ultra-endoscopic ultrasound needle, Wilson-Cook Medical Inc., 3 passes). The specimen was analyzed by a gastrointestinal specialized pathologist and was in keeping with the diagnosis of ESCC. The histology was confirmed by an immunohistochemical study with CD117, CD34, CD45, Be 12, Ker7, Ker20, Ker8-18 and 34 markers. 
With these findings, an upper gastrointestinal endoscopy was performed. It revealed a non-ulcerated suspicious lesion at the mid third of the esophagus, without stenosis (fig. 3 ). The diagnosis of infiltrative and moderately differentiated squamous cell carcinoma was confirmed by histology, special colorations (MowrieD and mucicarmin) and immunohistochemical markers (p63, CK5-6). The patient refused surgery or chemotherapy. He was referred for palliative radiotherapy for pain management.

\section{Discussion}

ESCC was not our initial hypothesis because of our patient's overall atypical presentation. First, the median age at diagnosis is 68 years with only $12 \%$ of patients between 45 and 54 years of age [3]. Our patient was a 53-year-old man. Second, he did not have dysphagia or odynophagia, which are the most common symptoms of esophageal cancer according to the literature [1]. His main symptom was abdominal pain that was also associated with postprandial abdominal fullness and vomiting. These were most likely due to extrinsic compression of the stomach by the abdominal mass. When pain is present in ESCC, it is usually thoracic or radiating to the back [1], but can occur less often in the upper abdomen [4]. Our patient also lost a significant amount of weight in 3 months $-21 \%$ of his total weight. When patients with esophageal cancer seek medical assistance, the majority experience anorexia and weight loss [1]. Weight loss seems to be an independent indicator of poor prognosis in esophageal cancer [4].

The retropancreatic mass is also an uncommon site of metastasis in esophageal cancer. With the rich esophageal lymphovascular supply, lymph node metastases occur early in ESCC [1]. On our patient's CT scan, the abdominal mass was not described as an adenopathy, but rather as a mass with heterogeneous necrotic tissue of unascertained origin. The initial hypotheses were gastrointestinal stromal tumor, lymphoma or sarcoma. A pancreatic neoplasm seemed less likely according to our radiologists. To our knowledge, an initial presentation of ESCC with an abdominal mass has not been reported, although there are few reports in the literature presenting some unusual metastatic presentations of ESCC, such as brain, myocardium, skin, jejunum, orbit, spleen, thyroid, Sister Mary Joseph's nodule or numb chin syndrome [6-14].

To establish the correct diagnosis of any abdominal mass, histology is indispensable in our opinion, especially if the patient does not present specific symptoms. Tissue sampling may be obtained by linear EUS [15] or by percutaneous needle biopsy under fluoroscopic, sonographic or CT guidance [4]. EUS provides both tissue sampling and an accurate evaluation of mass relationship with adjacent abdominal structures [15]. Since this technique is easily available in our center, we chose EUS for biopsy. Another important issue is that the esophageal lesion had not been identified at EUS. In our hospital, this procedure uses the linear scanning method that provides a limited wedge-shaped scanning plane. Therefore, it is possible to miss lesions if they are not in the scanning plane [15]. Hence, a gastroscopy was essential in the diagnosis of our patient's esophageal cancer, since it provides a proper evaluation of the esophagus.

Finally, ESCC is an aggressively invasive tumor [4]. With this large abdominal mass, our patient was diagnosed with a stage IV ESCC, according to the American Joint Committee on Cancer Staging system, rending surgery impossible [1]. The best treatment for our patient would have been concomitant radio-chemotherapy, which improves 5 -year survival in $25 \%$ of patients, whereas no patients survived 5 years 
using radiotherapy alone [16]. Our patient refused chemotherapy because of the possible side effects, but he accepted palliative radiotherapy to alleviate his abdominal pain.

\section{Conclusion}

To our knowledge, this is the first reported case of ESCC presenting as a large abdominal mass that was not an adenopathy. This case highlights that when a malignancy is suspected, it is important to establish a cytohistologic diagnosis. This can be safely achieved by EUS that will also evaluate extension of an upper abdominal mass. However, this technique does not replace gastroscopy to accurately identify esophageal cancer.

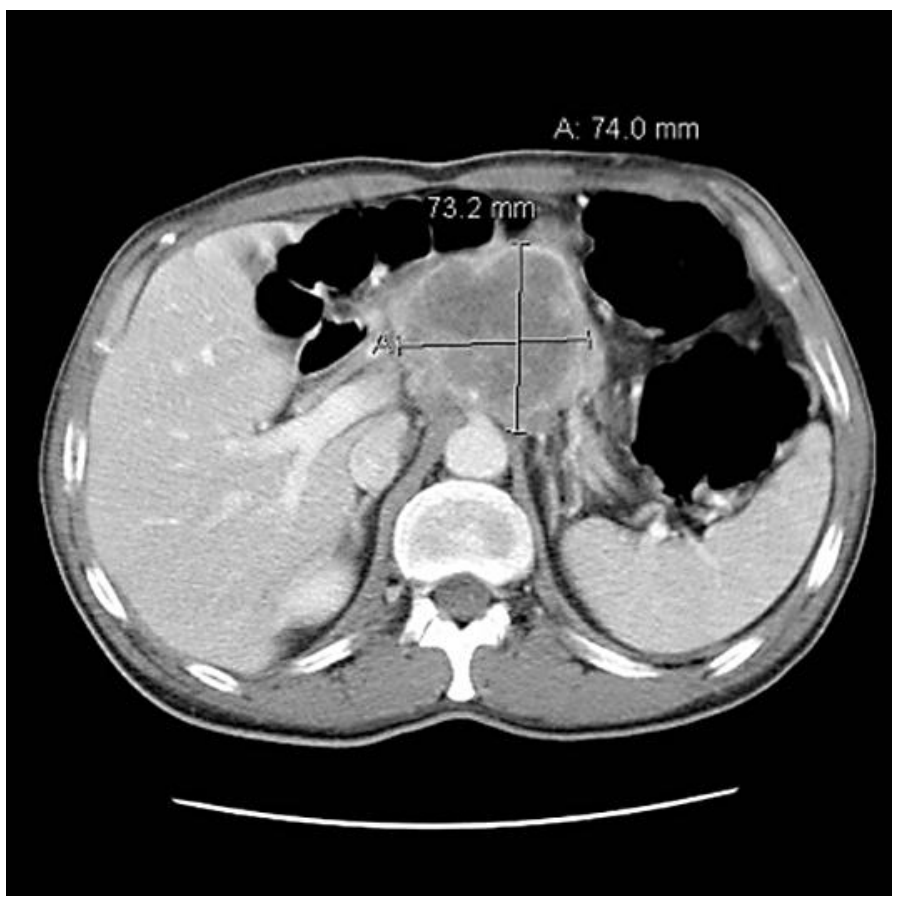

Fig. 1. CT scanning showing the heterogeneous mass localized beneath the pancreatic gland. 


\begin{tabular}{r|l|l|l}
$\begin{array}{r}\text { Case Reports in } \\
\text { Gastroenterology }\end{array}$ & $\begin{array}{l}\text { Case Rep Gastroenterol 2012;6:273-278 } \\
\text { DOI: 10.1159/000339211 }\end{array}$ & $\begin{array}{l}\text { Published online: } \\
\text { May 16, 2012 }\end{array}$ & $\begin{array}{l}\text { @ 2012 S. Karger AG, Basel } \\
\text { ISSN 1662-0631 } \\
\text { www.karger.com/crg }\end{array}$ \\
\hline
\end{tabular}

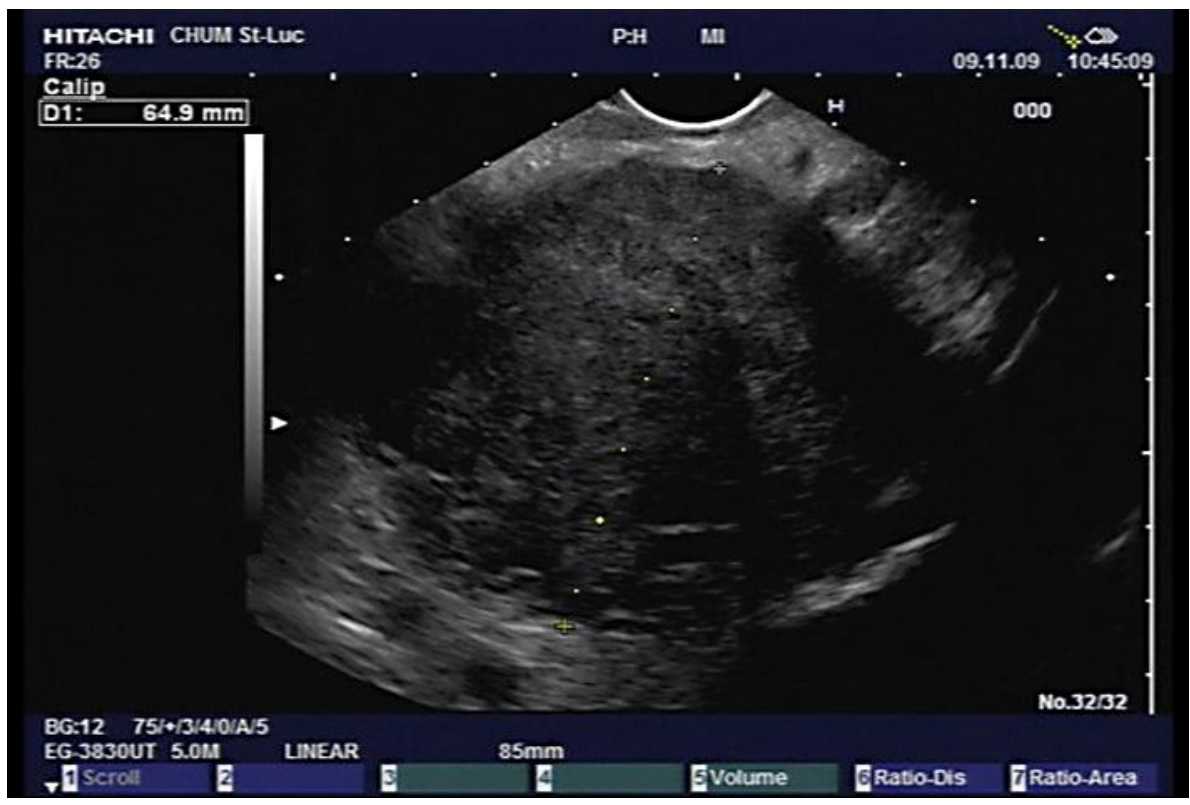

Fig. 2. The heterogeneous mass visualized with EUS.

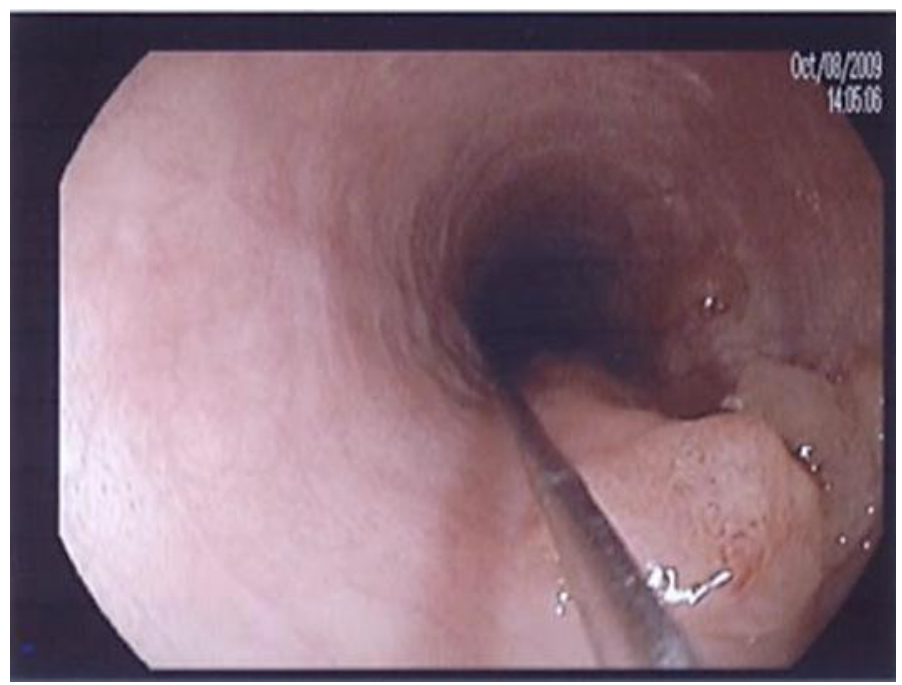

Fig. 3. Gastroscopy showing the suspicious lesion at the mid third of the esophagus. 


\section{References}

1 Feldman M, Friedman LS, Brandt LJ: Sleisenger \& Fordtran's Gastrointestinal and Liver Disease, ed 9. Philadelphia, Saunders, 2010, pp 745-767.

2 Canadian Society of Cancer: Canadian statistics of cancer 2009.

3 Alterkruse SF, Kosary CL, Krapcho M, Neyman N, Aminou R, Waldron W, Ruhl J, Howlader N, Tatalovich Z, Cho H, Mariotto A, Eisner MP, Lewis DR, Cronin K, Chen HS, Feuer EJ, Stinchcomb DG, Edwards BK (eds): SEER Cancer Statistics Review, 1975-2007, National Cancer Institute. Bethesda, MD, http://seer.cancer.gov/csr/1975_2007/, based on November 2009 SEER data submission (accessed February 21, 2011).

-4 Enzinger PC, Mayer RJ: Esophageal cancer. N Engl J Med 2003;349:2241-2252.

5 Wang KK, Wongkeesong M, Buttar NS: American Gastroenterological Association technical review on the role of the gastroenterologist in the management of esophageal carcinoma. Gastroenterology 2005;128:1471-1505.

-6 Yoshida S: Brain metastasis in patients with esophageal carcinoma. Surg Neurol 2007;67:288-290.

-7 Maeda M, et al: Myocardial metastasis from squamous cell carcinoma of the esophagus. Gen Thorac Cardiovasc Surg 2009;57:440-445.

8 Iwanski G, et al: Esophageal squamous cell carcinoma presenting with extensive skin lesions: a case report. J Med Case Reports 2008;2:115.

-9 Lindenmann J: Occult solitary submucosal jejunal metastasis from esophageal carcinoma. World J Surg Oncol 2005;3:44.

10 Tsai CK, et al: Anterior intraorbital metastasis from squamous cell carcinoma of the esophagus. Jpn J Ophthalmol 2008;52:408-410.

11 Cavanna L: Presentation of esophageal cancer with solitary splenic metastasis. Am J Clin Oncol 2005;28:636-637.

12 Narendra H, Ray S: Numb chin syndrome as a manifestation of metastatic squamous cell carcinoma of esophagus. J Cancer Res Ther 2009;5:49-51.

13 Basu S, et al: Squamous cell carcinoma of esophagus masquerading as solitary thyroid nodule. Indian J Cancer 2005;42:205-207.

14 Wijekoon NS, Samarasekera DN: Sister Mary Joseph's nodule as the sole presenting feature of disseminated squamous cell cancer of the esophagus: a rare case. J Gastrointest Cancer 2007;38:99-101.

15 Lam EC: Who needs an endoscopic ultrasound? Can J Gastroenterol 2005;19:657-659.

16 Créhange G, Maingon P, Bosset JF: Radiochemotherapy for oesophageal cancer: a locoregional failure history. Cancer Radiother 2008;12:640-648. 